\title{
Application of geocell in cold regions canal slope protection Wang Enliang ${ }^{1, a}$, FU Qiang ${ }^{1, b}$, Liu Xingchao ${ }^{1, c}$ \\ ${ }^{1}$ Northeast Agricultural University, Harbin150030, China \\ aHLJWEL@126.com, bfuqiang0629@126.com, cneauliuxing@163.com
}

Keywords: geocell, cold region, channel protection, frost damage protection

\begin{abstract}
Heilongjiang province is the lowest temperature provinces in China, the cold environment cause the freeze injury of the hydraulic engineering, the soil slopes of larger canal often collapse, so there is many difficulties in the water transmission of irrigation and draining canals and the engineering maintenance management. Through field survey, combined with the environment characteristics of cold regions, the damage characteristics and main reasons of soil slope was concluded. And the anti-freezing design practice was put forward, in order to protect the slope from being damaged. The geocell gravel structure was used in cold regions canal slope protection engineering project, through which the application effect of this structures was observed and evaluated. And the new way to protect the canal soil slope in cold regions was put forward.
\end{abstract}

\section{Introduction}

Heilongjiang Province is located at the cold regions in Northern China, and it is our country important commodity grain production base. It has water diversion irrigation channels and drainage channels thousands of kilometers in total. Frost heaving damage of canal engineering is very serious in seasonal frozen soil region and permafrost regions, channel need maintenance every year. This not only affects the normal operation of the engineering, but also wastes a lot of manpower, financial and material resources. The average water utilization efficiency in channels is only $0.5,{ }^{[1]}$ which is arising from severe channel permeation and freezing heaving damage. Therefore, seeking a technically reliable, technical, durable and easy construction channel slope protection technology is significant for recovering slopes beside the channels in Heilongjiang Province.

\section{Proposal of the design principle of frozen damage prevention}

The channel slope protection body is the bearing structure but the attached channel soil surface protection project, and the basic function is to prevent washing out and channel slope collapse. If the integrity is not damaged, proper deformation is permissible. According to experience in different areas, three kinds of normal direction displacement values in lining structure are proposed by Design code for anti-frost-heave of canal and its structure[2] (SL23 - 2006) (Ministry of Water Resources of the People's Republic of China 2006). Under the functions of the frost heaving and thaw collapsing, certain deformation (maximum residue deformation) of the lining can not affect design functions and use requirements of the channels. The protection body is the building allowing deformation.

Frost heaving of the frozen soil and collapse of the thawed soil are a kind of natural phenomenon for seasonal frozen soil, and a cycle process. In this process, functions of ice and water cause relocation and gravity transfer of the soil granules, which deforms the protection body. If the selected protection body, channel bed frozen soil and thawing soil feature can reach the best matching, it is possible to utilize the natural phenomenon to realize that the protection soil body heaves with the frozen soil and thaws with collapse of the soil and remove the damage to the slope.

Under the circumstances of unavailability of resistance and prevention, proposal of the frozen damage prevention technical route thinks that freezing heaving of frozen soil of the channel beds is natural. Freezing heaving and collapse of frozen soil are a necessary process, and the final residual deformation is permissible. When the permissible residual deformation is exceeded, it is called 
froze damage. Therefore, the engineering technical indexes of the frozen damage prevention technical route can be controlled by the residual deformation quantity and recovery rate. The service life can be calculated with performance of the protection materials.

\section{Geocell}

The geocell is a 3-dimensional net structure made of High Density Polyethylene (HDPE) with high-strength welding and is a special material in geotechnical synthesis materials. When used, stretch it out manually, and the interconnected strips form flexible 3-dimensional geocell. Add rubbles into the geocell to form the 3-dimensioanl grid structure. See Figure 1.

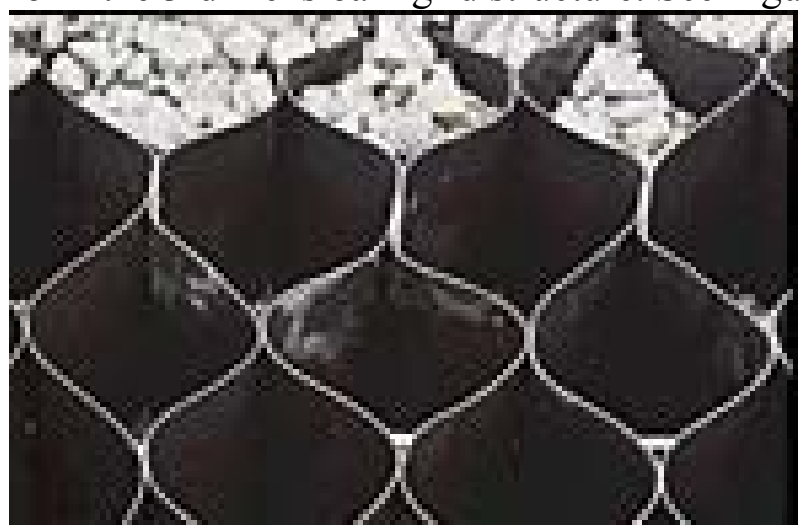

Fig. 1 geocell gravel structure

\subsection{Advantages of the geocell gravel structure slope}

The plastic geotechnical geocell are mainly made of the raw material polyethylene, which belongs to olefin group and has stable molecular structure. The carbon black aging resistance agent is added and the filled materials and surface plant covering can effective prevent ultraviolet, so service life of the geotechnical geocell is 40 years under the sunshine.

The geocell can prevents excessive displacements of the infilled soil because of the cell confinement and the redistribution of stresses to the underlying soil [3]. Geocell can increase soil strength by confinement, reducing lateral spreading and causing the confined composite to behave as a more rigid mattress [4]. Each net produces independent geocell and prevents the loosed fills from washed out by water and improve the erosion ability of the slope.

When sand, rubber and other loosen materials are filled in the geocell, an integral protection layer is formed on the slope. The material granules are large and belong to non-freezing heaving soil, without frost heave.

Owing to sound permeation of the protection layer of the slope, after the channel is out of water supply, water level in the slope can be quickly lowered within a short time, and the slope frost heave quantity is reduced, after thawing in spring, water in the thawing soil on the slope can permeate out quickly to reduce water content of the soil body near the channels, the shearing strength is increased and shallow landslide of the channels will not occur.

\subsection{Design of the geocell gravel structure slope protection}

Geocell is still not widely used at the same level as conventional methods such as piling, soil replacement, or traditional planar (geogrid or geotextile) basal reinforcement, due to the lack of design procedures for the use of geocells as basal reinforcement in many countries [5]. This paper proposed a design method of geocell taking the Hadashan Hydro Junction Project as the example.

Design of the geocell gravel structure slope protection is to determine the filled materials and depth and welding distance of the geocell.

(1) Selection of the filled materials: Success of the geotechnical grid slope protection relates to types of the filled materials and water flow rate. Diameters of the filled materials refer to the curve of the flow rate and rubble size (See Figure 2[6]). 


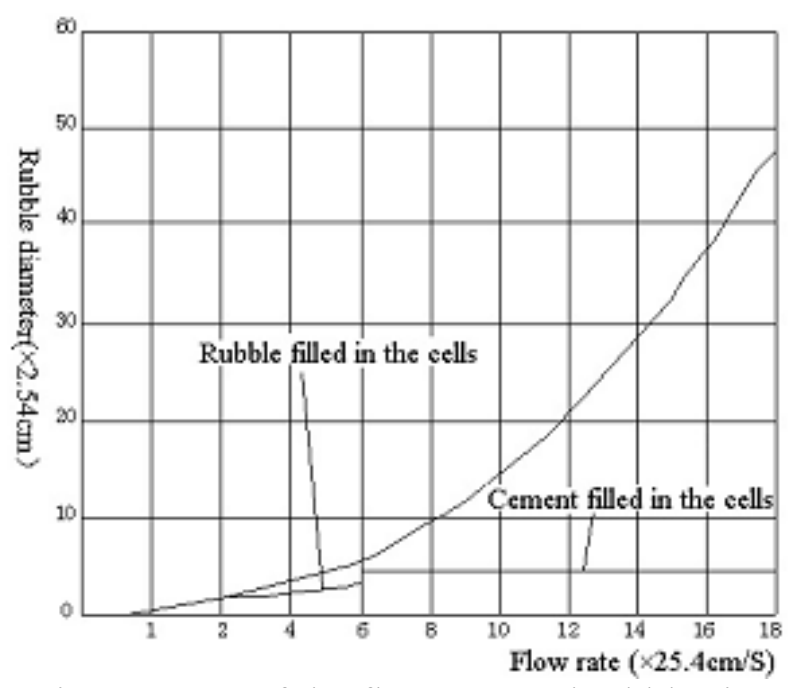

Fig. 2 Curve of the flow rate and rubble size

(2) Factors to be considered for selecting the grid sizes

The slope angle, surface radial flow strength and minimum angle of repose etc. should be considered for determination of depth, welding distance etc. At present, there is no standard method on the channel slope protection in cold regions. Selection of height and welding distance of the geotechnical geocell can only refer to existing projects of railway and highway.

\section{Application of channel slope protection in cold regions}

\subsection{Profile of Hadashan Hydro Junction Project}

Hadashan Hydro Junction Project (Stage 1) is located at the lower reaches of the 2nd Songhuajiang River trunk about $20 \mathrm{Km}$ from Songyuan City in the southeast in Jilin Province. The annual average temperature is $4.5^{\circ} \mathrm{C}$, the extreme low temperature in past years is $-37.8^{\circ} \mathrm{C}$, the freezing period last 5 months and it is the high cold region. The water conveyance main canal crosses Alluvial-proluvial Plain, Valley Alluvial Plain and Filled Lake Plain. The ground rock is clay, loam and other frost heaving soil. The water level of main canal is high. The uplift pressure, frost heaving and ice pushing resistance confronted by the channel lining are the technical difficulties which have not been solved yet.

To ensure science and feasibility of the water conveyance main canal lining design and long-term safe operation of the water conveyance main canal, the geocell gravel structure slope protection model is proposed, and the testing project is established for verification.

\subsection{Project design}

In accordance with geographical conditions and geological conditions of Hadashan water conveyance main canal, the principles for selecting the lining structure in the project are offered as follows: the first is employing flexible structure, which effectively adapts frost heaving deformation of the foundation soil quality, the second is reducing uplift pressure of the lining structure for underground water level. The structure used by the design has strong permeability and drainage, and the opening system can reduce frost heaving of the foundation soil, the third is improving integrity of the entire lining system. Integrity of the geocell gravel structure can minimize the damage force to the slope arising from the stock water after water subsiding in the channels in winter, the fourth is the desirable ecological effects. The growing space for plants can be provided above the lining system water level, with a sound ecological sightseeing effect.

Basic parameters: designed flow $100 \mathrm{~m} 3 / \mathrm{s}$, designed water level $137.84 \mathrm{~m}$, bottom elevation $133.32 \mathrm{~m}$, channel bottom width $28 \mathrm{~m}$, slope gradient $1: 2.5$, calculated wind speed $27 \mathrm{~m} / \mathrm{s}$, Fetch length $0.11 \mathrm{Km}$, the average depth of the waters $4.55 \mathrm{~m}$.

\subsubsection{Wave calculation}

According to GB50286-2013[7] (Code for design of levee project), the average wave height $\mathrm{H}$ is calculated as follows: 


$$
\left.\frac{g H}{V^{2}}=0.13 \operatorname{th}\left[0.7\left(\frac{g d}{V^{2}}\right)^{0.7}\right] \operatorname{th}\left\{\frac{0.0018\left(\frac{g F}{V^{2}}\right)^{0.45}}{0.13 \operatorname{th}\left[0.7\left(\frac{g d}{V^{2}}\right)^{0.7}\right.}\right]\right\}
$$

Where, $\quad g$-Acceleration of gravity, take $9.81 \mathrm{~m} / \mathrm{s}^{2}$

$H$ - The average wave height $(\mathrm{m})$

$V$ - Calculated wind speed $(\mathrm{m} / \mathrm{s})$

$F$ - Fetch length (m)

$d$ - The average depth of the waters (m)

According to the given parameters in the design materials, they are taken into the formula:

Where, $\quad H=0.167 \mathrm{~m}$

$$
\frac{g T}{V}=13.9\left(\frac{g H}{V^{2}}\right)^{0.5}
$$

Where, $\quad T=1.81 \mathrm{~s}$

$$
\begin{aligned}
& T-\text { The average wave cycle } \\
& L=\frac{g T^{2}}{2 \pi} t h \frac{2 \pi d}{L}
\end{aligned}
$$
$5.11 \mathrm{~m}$

Where, considering $\mathrm{g}=9.81 \mathrm{~m} / \mathrm{s} 2$ and $\mathrm{H}=0.167 \mathrm{~m}$, the average wave length (L) calculated was

\subsubsection{Selection of the filling materials}

According to $\mathrm{Yu}$ (1987) [8], define the provisional water depth when the wave is broken on the slope d0, the height of the wave peak A higher than the static water level H0, after the wave is broken, the wave peak particles impact the slope along the parabola in the form of jet flow, and the maximum wave flow produces at the intersection B of the jet flow and the slope (See Figure 3),

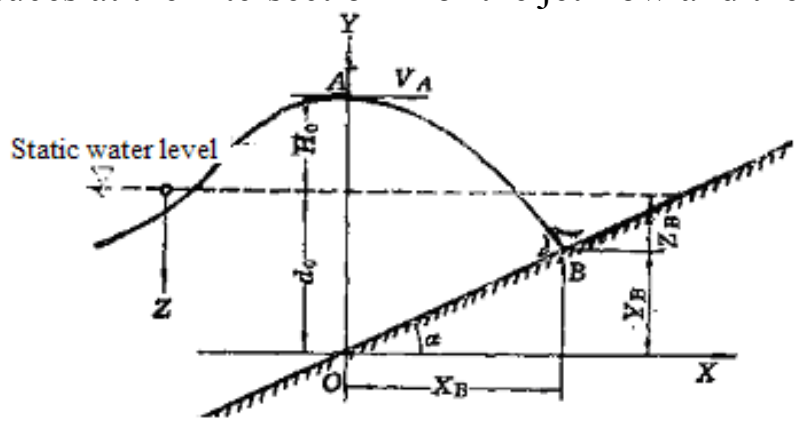

Fig. 3 Broken waves on the slope

Flow rate at point A:

$$
\begin{aligned}
& V_{A}=n \sqrt{\frac{g L}{2 \pi} \tanh \frac{2 \pi d}{L}}+H \sqrt{\frac{\pi g}{2 L} \operatorname{cth} \frac{2 \pi d}{L}} \\
& n=4.7 \frac{H}{L}+3.4\left(\frac{m}{\sqrt{1+m}}-0.85\right) \\
& V_{B X}=V_{A}
\end{aligned}
$$

Where, $\quad m=\cot \alpha$

$H$ - The wave height (m)

$L-$ The wave length $(\mathrm{m})$

$d$ - Water depth in front of the dam (m)

$g$-Acceleration of gravity, take $9.81 \mathrm{~m} / \mathrm{s}^{2}$

$V_{B X}$ - velocity component of $V_{B}$ in the X direction $(\mathrm{m} / \mathrm{s})$

Considering $V_{A}=1.06 \mathrm{~m} / \mathrm{s}, V_{B X}=1.06 \mathrm{~m} / \mathrm{s}>$ designed flow rate $=0.56 \mathrm{~m} / \mathrm{s}, d=8 \mathrm{~cm}$.

\subsubsection{Selection of sizes of the geocell}

Factors to be considered for selecting sizes of the geocell are: slope angle, surface radial flow strength and minimum angle of repose of the filled materials (See Figure 4). Relations of variations 
are offered below:

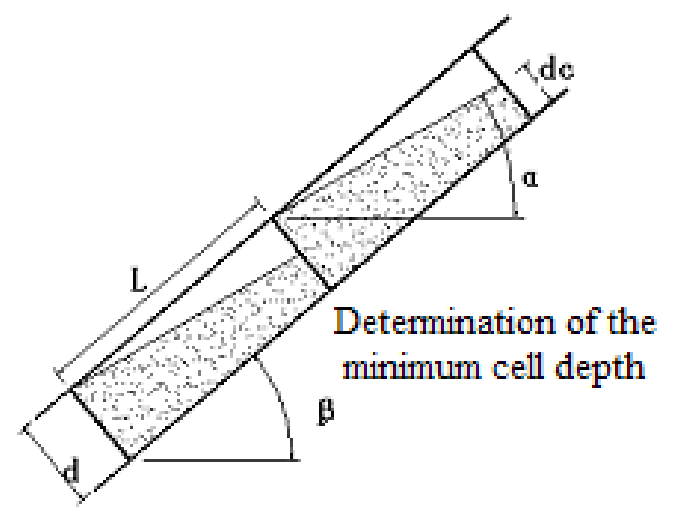

Fig. 4 Determination of the minimum grid depth

$$
\begin{aligned}
\alpha & =\beta-\arctan \left[\left(h-d_{c}\right) / l\right] \text { or } \\
h & =l \cdot \tan (\beta-\alpha)+d_{c}
\end{aligned}
$$

Where, $\alpha$-Minimum angle of repose of the filled materials

$\beta$ - Slope angle

$h$ - Depth of the geocell

$l$ - Length of the geocell

$d_{c}$ - Minimum permissible depth of the filled material

The minimum thickness with function of the waves can be calculated by the formula below:

$$
d_{c}=K_{1} \frac{\gamma}{\gamma_{b}-\gamma} \frac{H}{\sqrt{m}} \sqrt[3]{\frac{L}{H}}
$$

After taking parameters into it, $\mathrm{dc}=7 \mathrm{~cm}$

According to the calculation results, the rubber with graduation diameter $3-8 \mathrm{~cm}$ plus $300 \mathrm{~g} / \mathrm{m} 2$ polyester needling geotechnical fabric for anti-filtration, with the design height $200 \mathrm{~mm}$ and the welding distance $600 \mathrm{~mm}$. See Figure 5 on the structure schematic diagram of the geocell gravel structure.

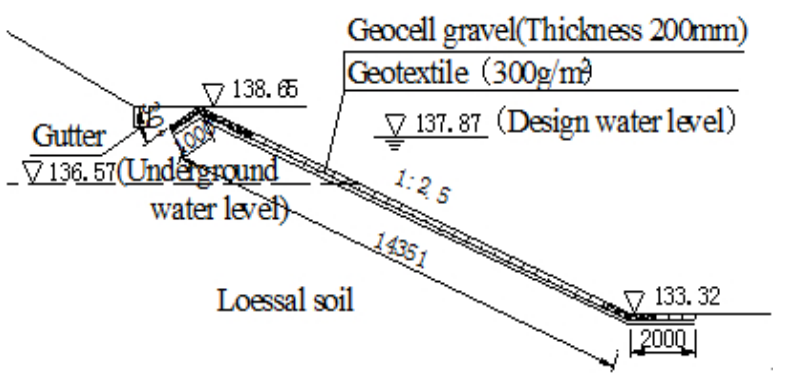

Fig. 5 Structure drawing of the geocell gravel $(\mathrm{mm})$

\subsection{Application effect}

The project test section was started in the last 10 days of November, 2008 and finished in the first 10 days of December. The area entered the freezing period in late November each year and completely thawed in April the following year. The channel slope deformation is stable after three freeze-thaw cycles.

See Figure 6 on the effect drawing of the geocell gravel structure slope protection after construction. 


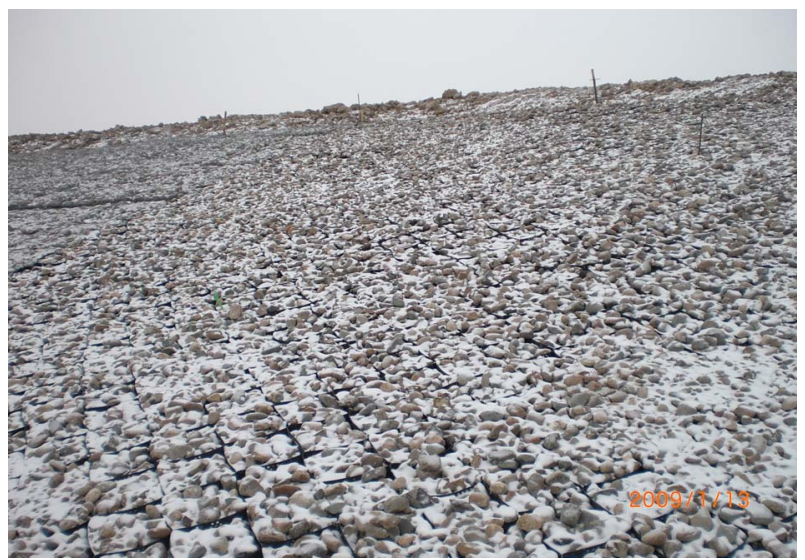

Fig. 6 Effect drawing of the geocell gravel structure slope protection after construction

\subsubsection{Economic benefits}

Geocell transport conveniently because it can expanse and shrink freely. Gravel can use local materials, so the construction is convenient. Time limit for a project can be shortened by $60 \%$ compared with the conventional method, saving a lot of transportation costs and labor costs.

The materials of the pile no. $47+215 \sim 47+240$ canal sections cost 64690.50 Yuan, which was reduced about $50 \%$ comparing to the conventional method. The geocell has a long service life and convenient maintenance, which can save a lot of manpower, material and financial resources.

\subsubsection{Ecological benefits}

The size of gravel used in the geocell is $8 \mathrm{~cm}$, the pore between the gravel can fill planting soil, which can plant grass and shrubs. Plant stem leaf can reduce the surface runoff and slow water flow. And stem leaf can reduce the wind speed, prevent soil erosion. Root can also consolidated soil to prevent soil erosion. Plant roots can also increase the porosity of the soil, increase the water permeability of soil, and filter effect.

Planting grass and bushes provide a good environment of air to nearby residents through afforesting environment, purifying air and absorbing the harmful substances in the air. Green plants also can form beautiful natural scenery to give people a good view.

\subsubsection{Engineering benefit}

Through the on-site observation and measurement in a freeze-thaw cycle, a collection for the observation and measurement results between the geocell gravel structure slope protection proposal and the contrast section without lining is made. See Table 1.

Table 1 Featured values of the freezing and thawing deformation of the tested sections (Unit: $\mathrm{cm}$ )

\begin{tabular}{ccccccc}
\hline \multirow{2}{*}{ Structure } & Value & \multicolumn{5}{c}{ Measurement points } \\
\cline { 2 - 7 } & & 1 & 2 & 3 & 4 & 5 \\
\hline \multirow{2}{*}{ Geocell gravel } & Max & 3.8 & 5.8 & 7.8 & 7.1 & 9.5 \\
\cline { 2 - 7 } & residual & 0.7 & -0.2 & -0.7 & -0.1 & 2.3 \\
\hline \multirow{2}{*}{$\begin{array}{c}\text { Without } \\
\text { protection section }\end{array}$} & Max & 4.2 & 7.3 & 9.1 & 7.9 & 11.6 \\
\cline { 2 - 7 } & residual & -0.3 & -0.5 & 1.7 & 0.2 & 1.6 \\
\hline
\end{tabular}

Known from Table 1, the maximum frost heaving of the observation points in the geocell gravel structure protection proposal is significantly smaller than that of the contrasted section without lining, with maximum $25.5 \%$ reduction of frost heaving. The residual deformation quantity of the geocell gravel structure slope protection plan is also significantly smaller than that of the contrasted section without lining. It is visible that, the geocell gravel structure can effectively reduce the frost heaving, meanwhile, the structure can adapt the freezing and thawing deformation well.

\section{Conclusion}

1) geocell gravel structure slope protection has the good economic efficiency. For it is convenient construction, short construction period and cost $50 \%$ less than traditional concrete 
prefabricated components.

2) Planting grass and bushes on the Geocell gravel structure slope protection helps to achieve a good ecological benefit, for it has the function of reducing soil erosion, preventing soil and water loss, purifying the air and beautifying the environment.

3) The geocell gravel structure can effectively reduce the frost heaving quantity and well adapt the freezing and thawing deformation.

\section{Acknowledgments}

This research was supported by Natural Science Foundation of Heilongjiang Province of China (E201405), Foundation of outstanding academic leaders project of Harbin science and technology bureau (2014RFXXJ103) and Postdoctoral funded projects of Heilongjiang Province of China (LBH-Z13031). The authors appreciate all the above support.

\section{References}

[1] S. Z. Peng and X. L. Gao: 'Discussion on improvement of irrigated water use coefficient', China Water Resour., 2012, 1, p 33-35.

[2] Water Resources Ministry of China: 'SL23-2006 (Design code for anti-frost-heave of canal and its structure)'. Beijing, p 17-18.(Chinese)

[3] B. Leshchinsky and H. I. Ling: 'Numerical modeling of behavior of railway ballasted structure with geocell confinement', Geotext. Geomembranes, 2013b, 36, p 33-43.

[4] H. Zhou and X. Wen: 'Model studies on geogrid- or geocell-reinforced sand cushion on soft soil', Geotext. Geomembranes, 2008, 26, p 231-238.

[5] L. Zhang and M. H. Zhao: 'Bearing capacity of geocell reinforcement in embankment engineering', Geotext. Geomembranes, 2010, 28, p 475-482.

[6] X. M. Qu, E. L. Wang and X. M. Yu: 'A Research on the Application of Geocells for Channel Side Slope Protection in Cold Regions', 5th Int. Symp. On 'Permafrost Engineering', Yakutsk, Russia. September 2002, p 208-213.

[7] Construction Ministry of China: 'GB50286-2013 (Dode for design of levee project)', Beijing, $p$ 57-59.(Chinese)

[8] G. M. Yu: 'Design of Wave Prevention Slope protection for Embankment', Beijing, China Water Power Press, 1987, p 126-129. (Chinese) 